\title{
O Uso de Jogos Educacionais do Tipo RPG na Educação
}

\author{
Anita Grando', Liane Tarouco ${ }^{2}$ \\ ${ }^{1}$ CINTED - Universidade Federal do Rio Grande do Sul (UFRGS) \\ 2Pós-Graduação Informática na Educação - UFRGS
}

\section{RESUMO}

Este artigo visa apresentar dentro dos aspectos pedagógicos os apontamentos que tornam relevante o uso dos jogos como um fator importante, mostrando como ele pode promover o processo de ensino e aprendizado entre os alunos dentro do âmbito escolar, como a sala de aula e laboratórios de informática educativa. Realizando uma verificação das estratégias dos diversos tipos de jogos que são utilizados nas diferentes formas de engajamento para uma aprendizagem mais efetiva.

Será abordando neste artigo a relação do trabalho com jogos digitais, visando dar ênfase para os do tipo RPG, citando suas características e potencialidades como jogo que pode, através de suas funcionalidades promover a cooperação e socialização, tornando-se uma excelente ferramenta educacional e interdisciplinar que pode ser trabalhado com alunos de várias faixas etárias.

PALAVRAS-CHAVE: Educação, jogos digitais, RPG, cooperação e socialização.

\section{INTRODUÇÃO}

A atividade de jogar precisa ser considerada em seu todo como uma forma de apoio dentro da educação para o desenvolvimento de muitas competências e habilidades do aluno, lhe servindo como estimulo enquanto este se encontra em faze de aprendizagem.

Neste contexto Piaget (1978) nos diz que o jogo é uma simples assimilação funcional ou reprodutória, e com a interiorização dos esquemas o jogo passa a assumir uma relevância maior no processo de assimilação, favorecendo assim o processo de desenvolvimento mental cognitivo.

Já no Brasil temos Passerino (1998) que nos descreve à relevância do trabalho com jogos educativos computadorizados para motivar o processo de ensino e aprendizagem, pois a utilização deste tipo de material, digital, une as características dos programas de computador e dos jogos. Trazendo assim vantagens que auxiliam na atividade do professor e na aprendizagem do aluno.

Prensky (2001) fala sobre as relevâncias do jogo no processo de aprendizagem, suas características e realiza uma comparação dos diversos tipos de jogos a serem utilizados nos diversos tipos de engajamento para uma aprendizagem mais interativa.

Há mais de três décadas, no Brasil, observam-se pesquisas e estudos em desenvolvimentos de jogos eletrônicos. A partir de 1992, iniciaram-se atividades relacionando o uso de jogos de RPG como elemento educacional.

A partir da verificação de que as atividades lúdicas sempre se encontraram no cotidiano do desenvolvimento lógico-cognitivo e social do indivíduo, desde a sua infância, passando pela adolescência até chegar à maioridade, assim, auxiliando este no desenvolvimento da criatividade, leitura, escrita, expressão verbal, organização do pensamento e do texto, convivência em grupo, argumentação entre outras competências sociais, além de manter viva dentro dele a imaginação e a fantasia.

Pode-se perceber que as atividades lúdicas auxiliam muitas capacidades, sendo assim, estas não deveriam ser mantidas nem somente usadas como suporte, na educação para o ensino de 
crianças na Educação Infantil e nos primeiros anos do Ensino Fundamental. Este tipo de atividade pode e deveria fazer parte do processo educacional e tipo de educação de cada indivíduo.

Pois atividades desenvolvidas em forma de jogo remetem o aluno a momentos de atividades agradáveis onde ele estará construindo o seu conhecimento e desenvolvendo suas potencialidades e características. Sendo assim, através de uma atividade lúdica, que é o jogo, o professor poderá, com criatividade e bom censo, elaborar atividades desafiadoras as quais serão realizadas pelos alunos de uma forma espontânea e voluntária.

$\mathrm{O}$ enfoque principal desta pesquisa será o trabalho realizado pelos professores e pesquisadores com os jogos do tipo RPG dentro das atividades lúdicas educacionais realizadas com jogos. Verificar o trabalho com o jogo em sala de aula usando RPG, se este nos permite trabalhar várias características importantes para o desenvolvimento de nosso aluno, como sujeito mais completo, no âmbito escolar, como: socialização, cooperação, criatividade, interatividade e interdisciplinaridade.

\section{O uso de jogos educacionais do tipo RPG Relevância do jogo como elemento educacional}

O jogo faz parte do cotidiano do ser humano desde muito tempo, sendo que na sociedade moderna cada vez mais os jogos invadem o nosso dia a dia das mais diversas formas e com as mais diversas propostas de entretenimento. Dentro desse processo percebe-se um crescente interesse pelos jogos eletrônicos (digitais), tanto pelos jovens como pelas crianças, onde se observou que em alguns adultos com idade entre 30 e 40 anos, os quais nasceram juntamente aos primeiros jogos eletrônicos comerciais e educacionais.

Conforme Prensky (2001) os jogos nos engajam, nos atraem, geralmente sem que nos demos conta. Essa força poderosa se originaria primeiro do fato de que eles são formados por diversão e brincadeiras e, segundo, pelo que ele chama de seis elementos-chave estruturais dos jogos: Regras, Objetivos e Metas, Resultados e Feedback, Conflito/Competição/Desafio/Oposição, Interação, Representação ou História. Entre os diversos tipos de jogos existem, os quais podem variar entre brincadeiras livres e jogos com regras. Prensky (2001) considera que os jogos em geral contêm a maioria, se não todos os fatores considerados por ele "fatores poderosos". Dentro destes fatores, o fator Regras é o que transforma um jogo em um jogo. Pois são elas que diferem o jogo da brincadeira. Brincadeiras são atividades livres e espontâneas, onde o indivíduo não precisa se preocupar em alcançar nenhum resultado, pois na brincadeira não temos implícita a competição entre os participantes, em contra partida no jogo esta situação já é intrínseca, onde co-existe a vitória e a derrota.

São as regras que nos orientam, organizam nossos passos, delimitam ações, estipulam o que pode e o que não pode ser feito, colocam limites para o certo e o não certo, nos orientam para alcançarmos as metas e que todos os participantes se encaminhem na mesma direção. As regras levariam a proposta pedagógica, onde os indivíduos encontrariam as indicações de como poderiam efetuar suas ações.

A meta ou o objetivo do jogo podem estar dentro das regras, são elas que nos impulsionam a alcançar a vitória e auxiliam a transformar a brincadeira livre em jogo. Dentro delas que se encontram as indicações para nossas expressões futuras na atividade, o que precisaremos fazer para completarmos cada etapa. Objetivos e regras se complementam fazendo com que o indivíduo se reorganize e crie estratégias específicas para continuar avançando dentro das etapas sem burlarmos as regras estabelecidas no início do jogo. 
São recursos que auxiliam a avaliar o progresso do jogador com relação as suas metas. Em muitos casos eles indicam no final do jogo se este foi ganho ou perdido em outros são mostrados a cada etapa Este artigo visa apresentar dentro dos aspectos pedagógicos os apontamentos que tornam relevante o uso dos jogos como um fator importante, mostrando como ele pode promover o processo de ensino e aprendizado entre os alunos dentro do âmbito escolar, como a sala de aula e laboratórios de informática educativa. Realizando uma verificação das estratégias dos diversos tipos de jogos que são utilizados nas diferentes formas de engajamento para uma aprendizagem mais efetiva.

Será abordando neste artigo a relação do trabalho com jogos digitais, visando dar ênfase para os do tipo RPG, citando suas características e potencialidades como jogo que pode, através de suas funcionalidades promover a cooperação e socialização, tornando-se uma excelente ferramenta educacional e interdisciplinar que pode ser trabalhado com alunos de várias faixas etárias.

Eles podem aparecer representados por um objeto (apito ou cartões do juiz de uma partida de futebol), forma numérica (no placar eletrônico nas provas de natação), pessoa (a voz indicando se está perto ou longe como nas brincadeiras de esconder) e gráficos (no painel de carros e motos de corrida). Trazendo-nos respostas imediatas as ações realizadas pelo jogador.

Os jogos de computador interativos são aqueles que possuem feedback que reagem as ações dos jogadores indicando as mudanças realizadas, estas podem ser indicadas através de sons, gráficos de força e vidas do jogador.

Dentro dos jogos educacionais além deles auxiliarem os alunos a verificarem o seu desempenho, eles também podem trazer dicas e informações sobre o que se está trabalhando, fazendo assim com que o aluno continue aprendendo durante o jogo sem que em um primeiro momento, não tenha que procurar informações em outro lugar para poder continuar sua atividade.

$\mathrm{Na}$ maioria das vezes os jogos envolvem algum tipo de conflito, desafio ou procura desafiar o jogar na resolução de algum problema. A partir deste ponto envolvente do jogo o professor pode desenvolver situações instigadoras que de uma forma lúdica façam o aluno procurar soluções para estas.

\section{Gênero de jogos}

Convivemos atualmente com duas grandes categorias de jogos, que são os convencionais, que são passados de geração em geração, e os digitais, mais atuais e presentes no cotidiano dos jovens e das crianças em idade escolar.

Os jogos convencionais possuem uma classificação conforme seu grau de interatividade. Já os digitais não possuem uma classificação específica.

Os jogos educacionais, conforme Vieira (apud ROMAN e STEYER, 2001) são categorias dentro da classificação de "software", os quais para a educação são categorizados conforme os seus objetivos pedagógicos: tutoriais, simulação, esporte, passatempo, aventura, jogos educacionais, exercícios e prática e RPG.

\section{RPG (Role-Playing Game)}

São jogos de representação de papéis, onde a cooperação e a criatividade são seus principais elementos. Eles seriam a forma digital da representação simbólica, onde a partir de fatos surgidos na imaginação da criança esta começa a realizar representações corporais e verbais sobre sua própria realidade ou uma criada por ela para resolver determinados conflitos.

Conforme Bittencourt \& Giraffa (2003), existem o "RPG de mesa" e o digital, no de mesa os jogadores vivenciam presencialmente a narrativa de uma história que deve ser interpretada pelos mesmos; já no digital esta mediação é realizada pelo computador através da web.

Alguns exemplos deste tipo de jogo são: Everquest, Neverwinter Nights e World of Warcraft 


\section{História e Características do gênero de jogo RPG}

O primeiro registro oficial do RPG (Role Playing Game ou jogo de representação de papéis) foi no ano de 1974. Sua primeira edição foi com o jogo Dungeons \& Dragons (abreviado como D\&D), idealizado pela empresa TSR dos Estados Unidos da América e criado por Gary Gygax. No início, o D\&D, ou "Calabouços \& Dragões" em português, era um simples complemento para um outro jogo de peças de miniatura chamado Chainmail (cota de malha), mas terminou dando origem a um jogo totalmente diferente e inovador.

Conforme o site da Associação LUDUS CULTURALIS (LUDUS, do latim, brincadeira e escola) a sigla RPG significa "jogo de interpretação". É um jogo, ou brincadeira de faz-de-conta, em que os participantes criam coletivamente histórias interativas. Um dos participantes, o Narrador, conduz a história como um roteirista ou diretor de cinema, enquanto os demais interpretam os personagens principais. Os demais participantes interpretam os Personagens principais, os heróis e as heroínas, e desempenha um papel ativo na história conduzida pelo Narrador. Portanto, uma sessão de RPG transforma-se numa atividade cooperativa em que todos os participantes colaboram na criação de uma narrativa oral de com características relativas a uma época ou momento específico. Entre as pessoas que tem o habito de jogar RPG, é comum ouvi-los dizer que a melhor maneira de entender a dinâmica de uma brincadeira como essa é brincando.

Eles consideram o RPG como uma brincadeira de faz-de-conta que pode envolver um número extremamente variável de participantes, das mais variadas faixas etárias. Numa sessão de RPG, um dos participantes torna-se o Narrador, dentro de um projeto pedagógico inicialmente que assumiria este papel seria o professor, ele que apresentaria para o seu grupo as regras, os objetivos, apresentaria os feedback (retomadas), realizaria a interação do grupo durante a sessão, que segundo Prensky (2001) são elementos chaves para a estruturação do jogo, e faria um fechamento a partir das ações dos jogadores.

\section{Referencial Teórico}

Em muitos momentos da história temos relatos sobre ações realizadas pelo homem (desenvolvimentos e descobertas). Dentre estas ações encontramos uma que faz parte dele desde seus primórdios (o jogo).

Para Piaget (1971) em um primeiro momento, o jogo é simples assimilação funcional ou reprodutória. Mas com a interiorização dos esquemas, o jogo diferencia-se ainda mais das condutas de adaptação propriamente ditas (inteligência), para orientar-se no sentido da assimilação como tal: em vez do pensamento objetivo, que procura submeter-se às experiências da realidade exterior, o jogo da imaginação constitui, com efeito, uma transposição simbólica que sujeita as coisas à atividade do indivíduo, sem regras e limitações. No nível dos primórdios da representação, o aspecto de cópia inerente ao símbolo como "significante", prolonga a imitação, as próprias significações, como "significados", podem oscilar entre a adaptação adequada que é própria da inteligência (assimilação e acomodação equilibradas) e a livre satisfação (assimilação que subordina a acomodação). Enfim, com a socialização da criança, o jogo adota regras ou adapta cada vez mais a imaginação simbólica aos dados da realidade, sob a forma de construções ainda espontâneas, mas imitando o real; sob essas duas formas, o símbolo de assimilação individual cede assim o passo, quer à regra coletiva, quer ao símbolo representativo ou objetivo, quer aos dois reunidos.

Dentro desta visão Piaget apresenta três grandes tipos de estruturas que caracterizam os jogos infantis e denominam a classificação de detalhe: exercício, o símbolo e a regra.

$\mathrm{O}$ autor considera que o desenvolvimento dos jogos de "construção" no indivíduo se constitui a partir da transição que se dá entre os três tipos de estruturas e as condutas de adaptação 
pelas qual o indivíduo passa e vai se apropriando. Aqui a estrutura que demonstra melhor as características que são desenvolvidas a partir das atividades realizadas com os jogos de RPG, são desenvolvidas durante o desenvolvimento das estruturas de Jogo Simbólico.

\section{Jogos símbolo}

Em um momento seguinte (entre 2 e 6 anos), Piaget (1978) nos fala que a criança começa a realizar representações corporais do seu imaginário. Neste momento na sua imaginação ela pode modificar a sua vontade. Usando o "faz de conta", mas quando expressa corporalmente as atividades, ela precisa respeitar a realidade concreta e as relações do mundo real.

As características dos jogos simbólicos são:

- $\quad$ liberdade de regras (menos as criadas pela criança);

- desenvolvimento da imaginação e da fantasia;

- $\quad$ ausência de objetivo explícito ou consciente para a criança;

- $\quad$ lógica própria com a realidade;

- $\quad$ assimilação da realidade ao "eu".

Então, pelo jogo simbólico, a criança exercita não só sua capacidade de pensar, ou seja, representar simbolicamente suas ações, mas também. Suas habilidades motoras, já que salta, corre, gira, transporta, rola, empurra, etc. Assim é que se transforma em pai ou mãe para seus bonecos ou diz que uma cadeira é um trem. Didaticamente devemos explorar com muita ênfase as imitações sem modelo, as dramatizações, os desenhos e pinturas, o faz de conta, a linguagem e muito mais; permitir que realizem os jogos simbólicos, sozinhas e com outras crianças, tão importantes para seu desenvolvimento cognitivo e para o equilíbrio emocional.

Este período caracteriza-se, principalmente, pela interiorização de esquemas de ação construídos no estágio anterior (sensório-motor).

A criança deste estágio apresenta as seguintes características:

- É egocêntrica, centrada em si mesma e não consegue se imaginar, no lugar do outro.

- Não aceita a idéia do acaso e tudo deve ter uma explicação (é a fase dos "por quês").

- Já pode agir por simulação, "como se".

- Possui percepção global sem discriminar detalhes.

- Deixa se levar pela aparência sem relacionar fatos.

Os esquemas constituídos pela interiorização dos esquemas de ação do período sensóriomotor são relevantes, pois auxiliam a criança na aquisição de vários tipos de conhecimentos, como reconhecimento de formas concretas dos objetos e formas ideais, auxiliando assim o indivíduo a conseguir realizar relações de comparações entre objetos concretos e figuras abstratas.

Passerino (1998) também fala da importância da utilização de atividades lúdicas no processo de ensino e aprendizagem através de jogos nas atividades educacionais, principalmente os jogos educacionais computadorizados, pois este reúne as características dos jogos com as do software. Ela diz que os jogos trazem consigo: entusiasmo, concentração, motivação, entre outros. Os jogos mantém uma relação estreita com construção do conhecimento e possui influência como elemento motivador no processo de ensino e aprendizagem (1998, p.1).

Passerino (1998), cita a existência de certos elementos que caracterizam os diversos tipos de jogos, características estas que podem para auxiliar no processo de ensino e aprendizagem, as quais que podem ser resumidos da seguinte forma:

- Capacidade de absorver o participante de maneira intensa e total (clima de entusiasmo, sentimento de exaltação e tensão seguidos por um estado de alegria e distensão). Envolvimento emocional

- Atmosfera de espontaneidade e criatividade. 
- Limitação de tempo: o jogo tem um estado inicial, um meio e um fim; isto é, tem um caráter dinâmico.

- Possibilidade de repetição

- Limitação do espaço: o espaço reservado seja qual for à forma que assuma é como um mundo temporário e fantástico.

- Existência de regras: cada jogo se processa de acordo com certas regras que determinam o que "vale" ou não dentro do mundo imaginário do jogo. O que auxilia no processo de integração social das crianças.

- Estimulação da imaginação, auto-afirmação e autonomia.

As atividades, de representação de papéis, relacionadas aos jogos do tipo RPG são bem antigas dentro do comportamento e desenvolvimento dos indivíduos nas sociedades no decorrer dos séculos, somente o termo é novo para nomear esta ação que perdura por séculos. Esta atividade de jogo onde os indivíduos se reúnem em pequenos ou grandes grupos para criar uma história coletiva e dar vida a seus personagens imaginários, principais características do RPG, também podem ser observadas em alguns tipos de brincadeiras infantis de representação.

Piaget em seus estudos descreve quatro (4) estágios de desenvolvimento mental cognitivo do sujeito e seus períodos através dos anos de vida do indivíduo, sensório-motor, pré-operatório (onde se desenvolvem os jogos simbólicos na criança), operatório concreto e operatório formal, onde estes se constituindo na modificação progressiva dos esquemas de assimilação. Piaget visualizou a evolução dos estágios em forma de uma espiral, de forma que cada estágio engloba o anterior o ampliando.

O autor não estipulou idade fechada para cada um dos estágios, apenas apresentou uma seqüência constante no aparecimento dos mesmos. Dessa forma o estágio citados por Piaget que descreve o desenvolvimento das habilidades ressaltadas pelo RPG :

- Pré-operatório (onde se desenvolvem os jogos simbólicos na criança):a criança desenvolve a capacidade simbólica; "já não depende unicamente de suas sensações, de seus movimentos, mas já distingue um significador(imagem, palavra ou símbolo) daquilo que ele significa(o objeto ausente), o significado

Com relação aos jogos de RPG pesquisados em livrarias e na rede mundial de Internet, percebi uma grande variedade e modelos do mesmo, alguns destes são tão abrangentes que a sua própria classificação se torna difícil de se definir seu grupo pertencente.

O essencial do RPG é que este é um jogo de interpretação de papéis, onde cada indivíduo dá vida a seu personagem através da construção das características físicas, sociais e habilidades do mesmo. Tendo uma história sendo narrada por um dos participantes que é denominado de Narrador, este por sua vez além de contar os fatos para os participantes também lhes dá informações sobre tudo que está acontecendo, fatos passados e futuros que venham auxiliar no desenvolvimento da história, ou sessão como se referem os praticantes.

Fazendo uma análise sobre os jogos do tipo RPG com relação aos estágios de desenvolvimento mental cognitivo citado por Piaget em seus estudos, pode-se considerar que a atividade de jogo simbólico, onde a criança realiza representação de papel, é o início para o desenvolvimento de atividades com os jogos tipo RPG, pois é neste estágio que o indivíduo começa a desenvolver as atividades de representação, socialização e cooperação que são à base deste tipo de jogo. Como pode-se ler na descrição da atividade de jogo infantil:

-Jogos infantis (mocinho e bandido, casinha).

Esta atividade de representação simbólica provavelmente é a mais antiga forma de se jogar RPG, ainda em uma forma onde os participantes não utilizariam tabuleiro e dados, pois apenas, 
ainda estariam representando um personagem, que terá uma vida temporária criada por ele. Encontramos muitas vezes um indivíduo, que por sua características próprias, acaba organizando a atividade e orientando os outros participantes como se este fosse o coordenador ou Narrador da história, ele pode vir a organizar tudo com ou sem o auxílio dos participantes e organiza as regras. Os resultados das ações são definidas pelo censo comum dos participantes, o que for bom para o grupo fica sendo aceito.

Considerando o relato descrito citarei e descreverei alguns outros exemplos já divulgados das mais variadas formas de se jogar RPG. Algumas são ações de representação simbólica, outros jogos concretos com o manuseio de fichas e dados, também têm formas eletrônicas e digitais de se praticar atividades de RPG:

- Tabletop role-playing game (RPG de mesa ou tabuleiro)

-Computer role-playing game

-Live action role-playing game

Eestes exemplos citados podem ser descritos da seguinte forma, conforme pesquisa realizada em livros e na internet:

-Dados e tabuleiro (exemplo: Dungeons \& Dragons)

Foi com a publicação de Dungeons \& Dragons em 1974 nos Estados Unidos que surgiu o RPG original, que se joga com livro, dados multifacetados, lápis e papel.

-LARPs (que vem do inglês Live-Action RolePlaying, ou " Ação Viva: Jogo de Interpretação de Papéis ", tradução literal) os primeiros LARPs evoluíram a partir dos RPGs de mesa

Ele é a versão mais atual para a brincadeira de representação simbólica, nele os participantes não utilizam o tabuleiro e os dados para joga e sim interpretam o seu personagem como se fossem atores, dando assim uma vida temporária para os personagens que eles criaram. Nele também encontramos o Narrador, o qual organiza e aplica as regras do jogo, no lugar dos dados os jogadores definem o resultado de uma disputa através de Jan Ken Po (pedra, papel e tesoura).

-RPG's por rede (MUD's)

Dentro da categoria dos RPG's de rede temos sub-divisões onde podemos ter as ferramentas de construção de RPG, os jogos assíncronos e os jogos em rede síncronos.

Os MUD's são programas antigos onde uma pessoa podia criar seu próprio mundo com suas regras. Este mundo poderia ser visitado por outras pessoas, as quais começariam a fazer parte deste interagindo com os outros jogadores e o Narrador. Devido a muita liberdade na construção dos mundos e das regras o sistema, inicialmente aberto para construções, começou a receber regras mais rígidas de comportamento dentro dos mundos, a partir da implementação destes novos sistemas de controle os MUD's acabaram sendo deixados de lado e substituídos por sistemas de mundos préprontos.

\section{O que se fala sobre o uso de jogos e em especial sobre RPG}

Para a introdução do computador na educação são necessários basicamente quatro ingredientes: o computador, o software educativo, o professor capacitado para usar o computador como meio educacional e o aluno.

No trabalho com software é necessária à utilização da exploração auto-dirigida ao invés da instrução explícita e direta

Para Passerino (1998, p.5) o jogo é uma atividade que tem valor educacional intrínseco e sendo assim a utilização de jogos educativos no ambiente escolar traz muitas vantagens para o processo de ensino e aprendizagem. 
Na visão de Passerino podem-se ter muitas vantagens com a utilização de jogos educativos no ambiente escolar, ela cita como sendo algumas destas vantagens que:

- O jogo é um impulsionador natural da criança e que funciona como um grande motivador durante as atividades

- O indivíduo através do jogo obtém prazer na atividade enquanto realiza um esforço espontâneo e voluntário para atingir o objetivo do jogo.

- O jogo desenvolve esquemas mentais: instiga o pensamento, estimula a ordenação de tempo e espaço.

- O jogo associa várias dimensões da personalidade do indivíduo: afetiva, social, motora e cognitiva.

- O jogo beneficia a aquisição de procedimento cognitivos e desenvolvimento de habilidades como coordenação, destreza, rapidez, força, concentração, etc

A pratica de jogos contribui para a formação de caráter sociais, como o respeito para com outra pessoa, ações de cooperação, respeito as regras, noção de responsabilidade, discernimento no momento de julgar, iniciativa própria e junto ao grupo.

\section{Quais as funções de um RPG que ensejam aprendizagem? Como?}

O RPG como toda e qualquer atividade educacional se for bem planejada e organizada pode se tornar uma ferramenta muito prática e lúdica, permitindo assim que os alunos aprendam de uma forma prazerosa. Ele pode ser uma ferramenta de suporte a educação muito boa, devido aos seus atrativos, com relação a ele ser um jogo que pode vir a despertar o lado lúdico da atividade e ao mesmo tempo em que auxiliar na assimilação de conhecimentos pelo aluno.

As características principais que auxiliam o jogo de RPG a se tornar uma excelente ferramenta educacional, são: socialização, cooperação, criatividade, interatividade e interdisciplinaridade.

Socialização: Devido aos participantes conversarem entre si e com o mestre (Narrador/Professor), trocando informações e relatando as ações de seus personagens. Todos desta forma elaboram uma história.

Cooperação: Para que o indivíduo seja bem sucedido mediante os desafios propostos pelo Narrador (coordenador) da história, ele precisará cooperar com os jogadores para que juntos concluam a atividade.

Criatividade: Cada um dos participantes desenvolve sua criatividade ao se imaginar na história e ao decidirem como os seus personagens reagem e resolvem os desafios das histórias. Eles também podem criar seus personagens, históricos e personalidades.

Interatividade: Os jogadores estão constantemente interagindo entre si e com o mestre. Atividades interativas comprovadamente levam a uma maior fixação de conteúdo do que atividades expositivas.

Interdisciplinaridade: Uma única história pode abordar temas de várias disciplinas harmonicamente. No exemplo proposto acima, a história pode abordar elementos de História (a época em que se passa a história), Geografia (o local da história, atividades humanas) e Biologia (conhecimentos de botânica da curandeira, Ecologia para o caçador). Outros elementos podem ser adicionados. Por exemplo. Uma outra história pode abordar um disparo de canhão contra um navio inimigo. A trajetória do tiro versus a velocidade de deslocamento do navio aborda elementos de Física e Matemática, além de História.

Pois o RPG e é o modelo que os professores, que estão usando RPG, pretendem usar com os alunos para se fazer uma aprendizagem mais efetiva. 


\section{Quem está usando RPG e como}

Os jogos do tipo RPG se encontram no mercado desde a década de 70, onde se começou com os jogos de tabuleiro e dados multifacetados e coloridos. A partir da metade da década de $80 \mathrm{o}$ RPG digital entra em cena, ainda com algumas versões do tipo Play-by-mail gaming e outras como MUD's.

Em 2002, a LUDUS CULTURALIS, uma associação civil sem fins lucrativos, realizou o pioneiríssimo Simpósio RPG \& Educação, em São Paulo - SP, promovendo o intercâmbio entre pesquisadores e também o contato de centenas de educadores com os trabalhos desenvolvidos até então. Novas edições do simpósio vieram em 2003 e 2004, acompanhadas por um aumento significativo na participação do público e no número de palestrantes inscritos.

\section{Atividades realizadas}

Além do Simpósio realizado pela LUDUS CULTURALIS, temos outras manifestações no Brasil desenvolvidas por escolas particulares.

Dois colégios do estado do Rio de Janeiro que realizam atividades utilizando o RPG como ferramenta de apoio para o desenvolvimento das atividades educacionais, para potencializar o processo de ensino aprendizagem, no Colégio Andrews (Rio de Janeiro-RJ) e no Colégio CEL (Rio de Janeiro-RJ)

O estado do Rio Grande do Sul também participa de atividades voltados a potencialização do processo de ensino aprendizagem, a Feiras de Livro em escolas do Grande Rio

Dentre todas as opções contidas no jogo de RPG, este por sua vez trabalha o estímulo à socialização, cooperação, criatividade e ao hábito da leitura.

Projeto do RPG como ferramenta educacional (vivenciar algo estimula o seu aprendizado e permite uma maior retenção do conhecimento adquirido), com treinamento de Mestres, criação de aventuras ou apostilas em forma de livro-jogo, etc.

\section{Construtores de jogos RPG}

Atualmente um dos principais nomes no trabalho e construção de RPG e principalmente RPG educacionais é Carlos Klimick, iniciou no mercado editorial de jogos e entretenimento em 1992, com a criação do primeiro RPG com temática nacional, o "DESAFIO DOS BANDEIRANTES”. Este se encontra acompanhado de Flávio Andrade. Além da co-autoria do "DESAFIO DOS BANDEIRANTES" e da linha de RPG's da Akritó, também atuou como editor e diagramador.

A partir deste primeiro trabalho de desenvolvimento de um RPG com temática nacional acabou por se tornar uma série de novos materiais, eles vêm criando e divulgando vários outros materiais, onde alguns são complementações para seu primeiro trabalho e outros com outros enredos, sendo todos com fins educacionais.

\section{Ferramentas utilizadas para a construção de jogos RPG}

Atualmente a ferramenta mais conhecida para se construir jogos do tipo RPG é o RPG Maker, ele faz parte de uma série de programas para desenvolvimento de jogos de RPGs, criada pela empresa ASCII (e depois continuada pela Enterbrain). Permitindo que os usuários criem seus próprios jogos de RPG eletrônicos, com criar mapas utilizando tilesets, programar acontecimentos no jogo através de comandos de eventos pré-programados, entre outras funções. 


\section{CONCLUSÕES}

Nós como educadores precisamos romper com a visão de que o RPG é apenas um jogo, e a partir da prática descobrir todo o potencial para ensejar a educação, que existe oculto nos programas de RPG . Fazendo assim com que nossos alunos tenham mais autonomia e responsabilidade na construção de seu conhecimento através da elaboração de seus próprios grupos de pesquisa para a construção de suas "histórias".

Pois quando o aluno realiza pesquisas pertinentes a aplicações de seu interesse seu aprendizado é muito mais significativo ao contrário de realizar uma pesquisa

Sendo assim podemos perceber que alunos e professores podem trabalhar juntos para cada vez mais melhorarmos a situação da educação dentro dos ambientes escolares tradicionais. As instituições de ensino e aprendizagem podem em sua estrutura se manterem convencionais, porém a forma de ensinar os alunos precisa ser reformulada

\section{REFERÊNCIAS}

BITTENCOURT, João Ricardo. GIRAFFA, Lucia Maria. Modelando Ambientes de Aprendizagem Virtuais utilizando Role-Play-Games. Simpósio Brasileiro de Informática na Educação - "Inclusão digital como instrumento de inclusão social". Rio de Janeiro. Universidade Federal do Rio de Janeiro. 2003

BOARD, Game Bulletin. The Ultimate RPG MAKER for Windows! RPG MAKER XP. 31 ja. 2006. Disponível em: <http://www.enterbrain.co.jp/tkool/RPG_XP/eng/index.html> Acesso em: 15 dez. 2006

FARIA, Anália Rodrigues de. O pensamento e a linguagem da criança segundo Piaget. Ed. Ática S.A., São Paulo, 1995.

JUNIOR, Ivar P. Mas que diabos é isso? Live-action online. Disponível em: <http://www.ivar.hpg.ig.com.br/oquesao.htm> Acesso em: 25 nov. 2006

KISHIMOTO, Tizuko "Jogos infantis: o jogo, a criança e a educação" São Paulo: Vozes, 1993.

KLIMICK, Carlos. Editores. AKRITÓ RPG. Disponível em:

<http://www.akrito.com.br/editora/curricl.htm> Acesso em: 17 nov. 2006

KLIMICK, Carlos. O Desafio dos Bandeirantes: Um RPG 100\% nacional. Disponível em:

<http://www.nautilus.com.br/ ensjo/rpg/oddb/> Acesso em: 14 out. 2006

LUDUS CULTURALIS. Associação LUDUS CULTURALIS. 2002. Disponível em: <http://www.ludusculturalis.org.br/> Acesso em: 15 SET. 2006

MORAES, Raquel de Almeida. Informática na Educação. Rio de Janeiro: DP\&A, 2000.

PASSERINO, L.M. (1998). Avaliação de jogos educativos computadorizados. Disponível em:

<http://www.c5.cl/tise98/html/trabajos/jogosed/> Acesso em: 20 out. 2006

PIAGET, Jean. A formação do símbolo na criança : imitação, jogo e sonho, imagem e representação. 3. ed. Rio de Janeiro: Zahar, 1978.

PRENSKY, Marc. Digital Game-Based Learning. McGraw-Hill, 2001

SILVA, Mozart Linhares da. Novas tecnologias - educação e sociedade na era da informação / organizado por Mozart Linhares da Silva. Belo Horizonte. Autêntica. 2001.

VALENTE, Jose Armando. Educaçao A Distancia Via Internet. Avercamp. São Paulo, $1^{\text {a }}$ Edição 2003 - 204 pág.

ZIMMERMMAN, Mayara. Projeto de Educação nas Escolas envolvendo o RPG. REDERPG.

2005. Disponível em: <http://www.rederpg.com.br/portal/modules/news/article.php?storyid=2183>

Acesso em: 24 set. 2006 